\title{
POROSITY EVALUATION OF FLAME-SPRAYED AND HEAT- TREATED NICKEL-BASED COATINGS USING IMAGE ANALYSIS
}

\author{
ZORAN BERGANT AND JANEZ GRUM \\ Faculty of Mechanical Engineering, Askerceva 6, 1000 Ljubljana \\ e-mail: zoran.bergant@fs.uni-lj.si; janez.grum@fs.uni-lj.si \\ (Accepted Jannuary 27, 2011)
}

\begin{abstract}
Flame sprayed coatings are susceptible to the formation of inter-connected elongated porosity due to the lack of fusion between sprayed particles or the expansion of gases generated during the spraying process. The partial remelting of self-fluxing Ni-Cr-B-Si coating after spraying is an efficient method to reduce porosity and to improve coating microstructural and mechanical properties. The paper describes the image preprocessing procedure for noise removal which separates the pores from the background and the noise. The optimal temperature and time of a furnace heat treatment of $\mathrm{Ni}-\mathrm{Cr}-\mathrm{B}-\mathrm{Si}$ coated specimens was determined by using a three-level factorial experiment. The purpose was to obtain the lowest possible porosity. Equivalent diameter, elongation, and major axis angle were analyzed and compared using probability density functions. The experiment shows zero-percent porosity cannot be obtained with a partial remelting of flame-sprayed Ni-Cr-B-Si coatings; however, porosity can be greatly reduced. This method of coating post-processing not only favours pore size and shape but also eliminates the undesired network of interconnected elongated pores.
\end{abstract}

Keywords: coatings, flame spraying, image analysis, lamellar structures, porosity.

\section{INTRODUCTION}

The Ni-Cr-B-Si coatings are used for wear and corrosion protection of parts and components operating at elevated temperatures. The powder flame-spraying method is a well established method for coating deposition. The spherical powder particles are partially or fully melted with an oxygen-acetylene flame and separate into a number of small droplets. They are accelerated in a turbulent flow of gases and deposited on the rough substrate surface forming a coating with a porous, lamellar and heterogeneous microstructure with oxide layers (Shrestha et al., 2001; Davis, 2004,). Powder flame-sprayed coatings are susceptible to the formation of pores of irregular shape and interconnected elongated porosity which occurs because of a lack of fusion between the sprayed particles or expansion of gases generated during the spraying process. Irregular and elongated pores are stress concentrators and susceptible to brittle cracking. This reduces the coated part's operating time under severe loading conditions, as it is subjected to stress-corrosion, erosion, and fatigue. The partial-remelting of selffluxing Ni-Cr-B-Si coating after spraying is an efficient method for reducing porosity to improve the coating's microstructure and mechanical properties. During the remelting process, the metallurgical and chemical phenomena in Ni-Cr-B-Si coating lead to de-oxidation reactions and gas extraction which improve microstructure, microhardness, adhesion and corrosion properties (Gonzales et al., 2007; Bergant and Grum, 2009; Serres et al., 2010). Formation of a liquid eutectic phase at a relatively low temperature enables filling up the voids of a solid matrix phase with a liquid material and thus reduces the coating's porosity. Determination of porosity is important to monitor the effect of variable flame-spray parameters or subsequent heat-treatment as well as the suitability of a coating for its intended purpose.

In material research applications, different methods were proposed to discriminate lamellar structures from spheroidal objects. A so called ribbon-like method was proposed for measuring particles for discrimination lamellae from spheroids of cementite particles in pearlitic steels (Nutal et al., 2010). Volumetric and area fraction methods were used to extract the characteristic pore sizes in pervious concretes for permeability prediction (Neithalath et al., 2010). The method for discriminating thin lamellar pores from spherical pores was also proposed by an "opening" operation performed on the binary image for characterization of porosity in thermal sprayed ceramic coatings (Desphande et al., 2004). Stereometric analysis was used to evaluate linear and spatial parameters of pores in Ni-Cr-B-Si 
coatings under the idealised presumption that a pore in in spray coating is almost an equiaxial spherical void with no sharp edges (Kumar, 2000).

Many of the important digital image processing techniques that are now in widespread usage were first implemented for application in microscopy. At this point in time digital image processing is integral part of microscopy and only rarely will one see a microscope used with only visual observation of photography (Kenneth et al., 2008). Appropriate image pre-processing procedures enable separation of the pores from other microstructural features, such as interface and other artefacts. The key element of image pre-processing is to select appropriate segmentation and noise reduction methods for various applications. The object classification analysis characterize the contents of the image. Assuming the objects in the image have been segmented and measured, classification identifies them by assigning each of them to one of several previously established categories or classes.

\section{MATERIALS AND METHODS}

The aim of the research was to find optimal temperature-time conditions for the furnace partial remelting of self-fluxing NiCrBSi coating used to minimize apparent porosity. The factorial design of experiment method was used to obtain technological data, including parameter significance (Montgomery, 2008).

\section{SUBSTRATE AND POWDER MATERIAL}

The substrate for specimen preparation is colddrawn round profile, made from soft low-carbon steel W.No. 1.0037 (SIST EN 10027-2). Fig. 1a reveals the ferrite-pearlite microstructure of the soft carbon steel with directional oriented pearlite grains. Fig. 1b shows the spherical morphology of nitrogen atomized powder particles Ni-Cr-B-Si under the SEM microscope. The chemical composition of both substrate and powder material is given in Table 1.

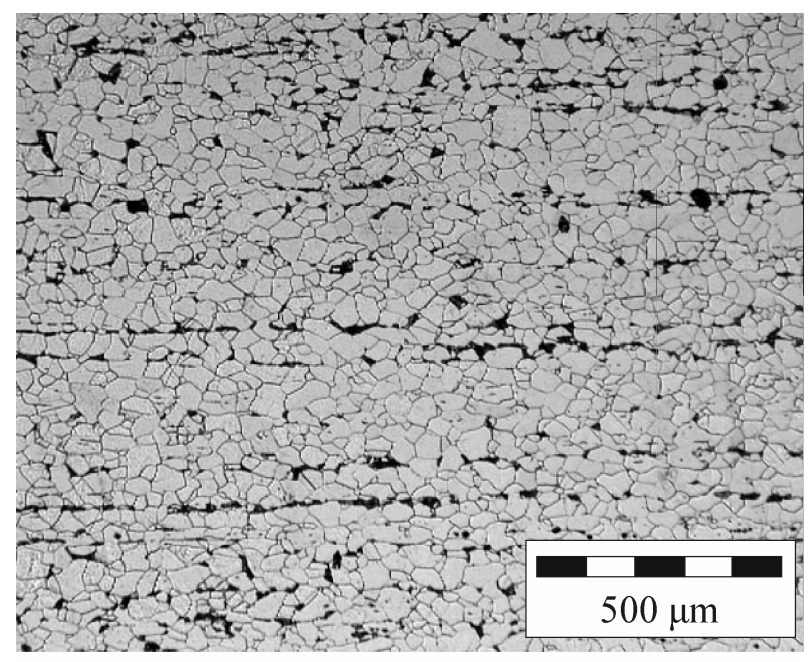

(a)

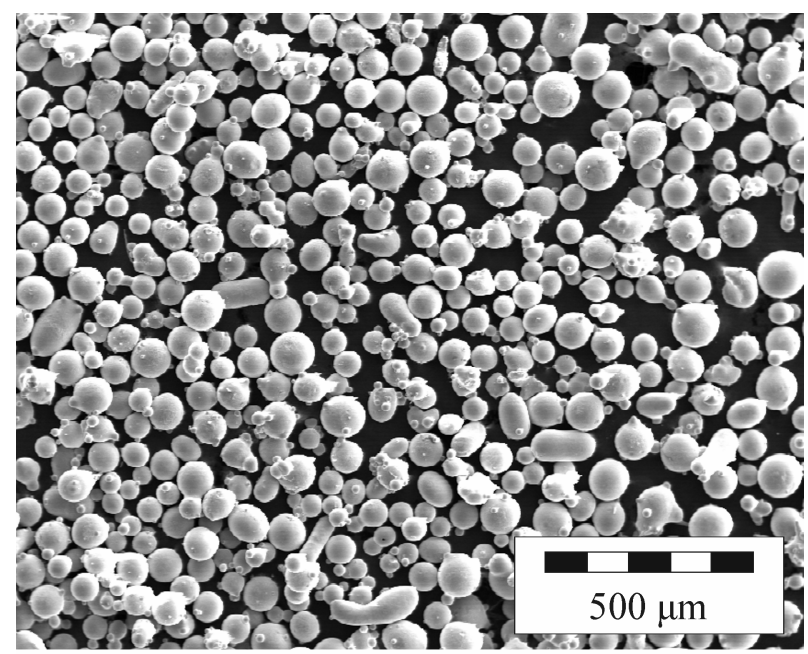

(b)

Fig. 1. Substrate and powder spraying material (a) ferrite-pearlite substrate microstructure, (b) SEM image of $\mathrm{Ni}$-Cr-B-Si powder particles.

Table 1. Chemical composition of the substrate and powder material (in weight percentage, wt.\%) made of powder $\mathrm{Ni}-\mathrm{Cr}-\mathrm{B}-\mathrm{Si}$ and base material from low-carbon steel substrate.

\begin{tabular}{ccccccccc}
\hline Wt. [\%] & $\mathrm{Ni}$ & $\mathrm{Cr}$ & $\mathrm{B}$ & $\mathrm{Si}$ & $\mathrm{Fe}$ & $\mathrm{C}$ & $\mathrm{Mn}$ & Mo \\
\hline Powder Ni-Cr-B-Si & 78.1 & 13 & 2.08 & 3.22 & 3.09 & 0.51 & - & 0.047 \\
Substrate 1.0037 & 0.18 & 0.1 & - & 0.17 & bal. & 0.08 & 0.45 & - \\
\hline
\end{tabular}




\section{COATING DEPOSITION}

The coating was deposited onto a face surface of cylindrical specimens, with a diameter of $25 \mathrm{~mm}$ and a length of $25 \mathrm{~mm}$, using the flame-spraying torch "Rototec 80 ". The specimens were mounted on the drum and a torch holder with constant rotation of 18 $\mathrm{rev} / \mathrm{min}$ and feed $2 \mathrm{~mm} / \mathrm{rev}$. During the rotation, the powder flow was turned on at a point without specimens and was completed after 10 passes through the specimens. The spraying distance was set to 200 $\mathrm{mm}$. The oxygen working pressure was set to 4 bar and acetylene to 0.4 bar. An average coating thickness of $0.4 \mathrm{~mm}$ was obtained. After remelting, the coating thickness was reduced by approximately $20 \%$.

\section{HEAT TREATMENT}

Heat treatment was performed on nine samples in a furnace with a protective argon atmosphere. Nine combinations of temperature and time values were used according to $3^{2}$ full-factorial experimental design (Montgomery, 2008) to study two parameters at three levels. The temperature range investigated was between 930 and $1080^{\circ} \mathrm{C}$. The first temperature level was selected at $930^{\circ} \mathrm{C}$ to examine the effect of overheating on microstructure. The second temperature level at $1040^{\circ} \mathrm{C}$ is the melting point of the eutectic stage of the solid austenite matrix phase where the densification of the coating may occur. The highest temperature level at $1080^{\circ} \mathrm{C}$ is $30^{\circ} \mathrm{C}$ below the liquid line of the Ni-Cr-B-Si alloy where the solid phase prevents liquid-phase flow from the surface. A relatively short time period was chosen for the heattreatment process, namely, 5, 10, and 20 minutes, based on the manufacturer's data and scientific literature on the remelting of the Ni-Cr-B-Si alloy (Shrestha et al., 2001; Kim et al., 2003). Fig. 2 represents the experimental procedure of coating deposition, heat treatment, and metallographic specimen preparation for the image analysis.

\section{METALLOGRAPHIC ANALYSIS}

In metallography, the methods of counting and measuring the pores are performed on a 2-D surface of the metallographic specimen. The test method for determining area percentage porosity in thermal sprayed coatings is described in the standard ASTM E210901. It includes the direct comparison method of a metallographic image and referential images with known area percentage porosity and a method using the computerized image analysis approach.

\section{SAMPLE PREPARATION AND IMAGE PRE-PROCESSING}

The metallographic specimens were prepared in the standard procedure (ASTM E 1920-03) used in thermal sprayed coatings. The etching was performed in nital (10\% nitric acid $\mathrm{HNO} 3$ in ethanol) to reveal the base material microstructure without effecting the polished Ni-Cr-B-Si coating microstructure. Grey images of the polished Ni-Cr-B-Si coating were used for subsequent image segmentation and noise reduction. They were obtained at 50 times objective magnification and aperture 0,18 using the Leitz Wetzlar microscope and the Olympus Colorview integrated camera.

Initial images were taken in a dark room to avoid the influence of outside light to minimize the contrast and brightness variation.

Image post-processing with AnalysisDocu was performed for RGB separation to convert RGB color image to grey scale images, Photoshop CS2 for cropping, thresholding, and median noise reduction, and ImageTool v3 for pore shape analysis. For each image, a square analysis field was selected from image, with a width of $1000 \mu \mathrm{m}$. The image with the measuring field is given in Fig. 3a, histogram of grayscale image of cropped image on Fig. $3 \mathrm{~b}$ and image after binarisation in Fig. 3d.

Quantitative metallography for pore shape analysis was performed on the binary (black-white) images. The segmentation process using threshold function was used to transform the monochromatic image with 255 gray shades into the binary image with black and white pixels.

The threshold separates the background form the pores and transforms the grey image into the binary. In present image pre-processing procedure, the median filter was used after binarisation although the median filter is usually done in grayscale image. 


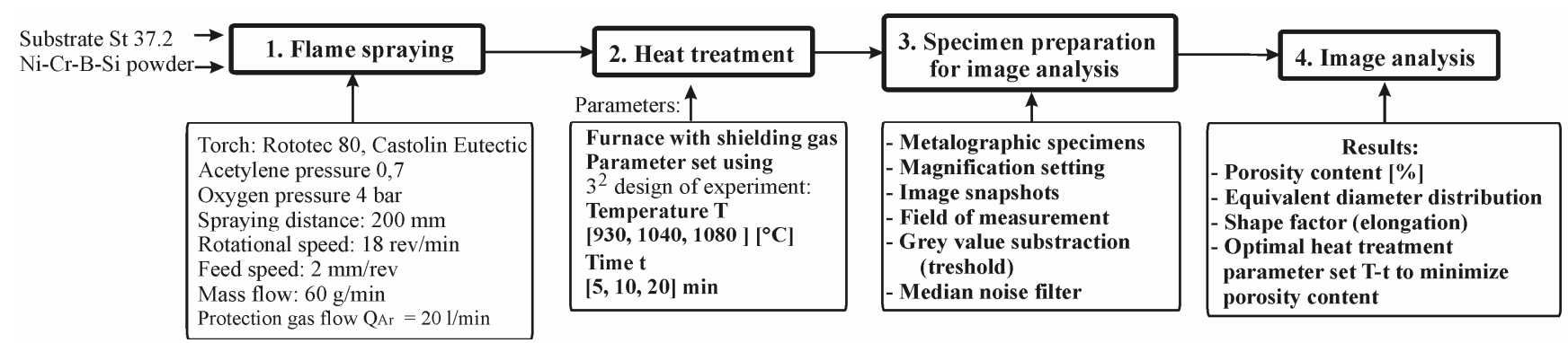

Fig. 2. Experimental procedure of specimen and image pre-processing.

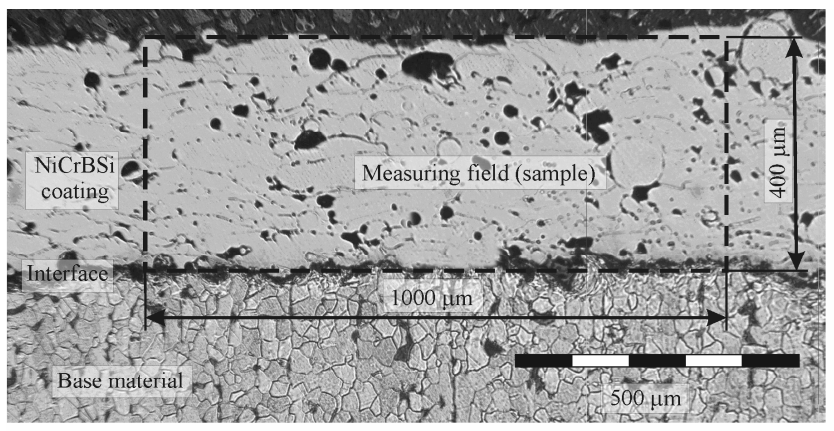

(a) Initial image of coating and base material in gray-scale [0-255]

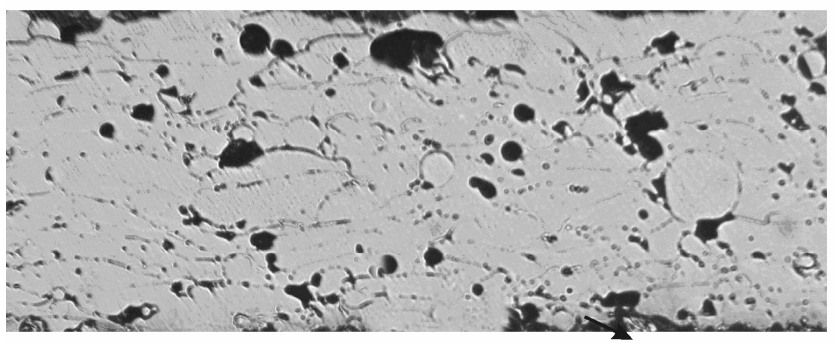

(c) Croped initial image of coating in gray scale [0-255]

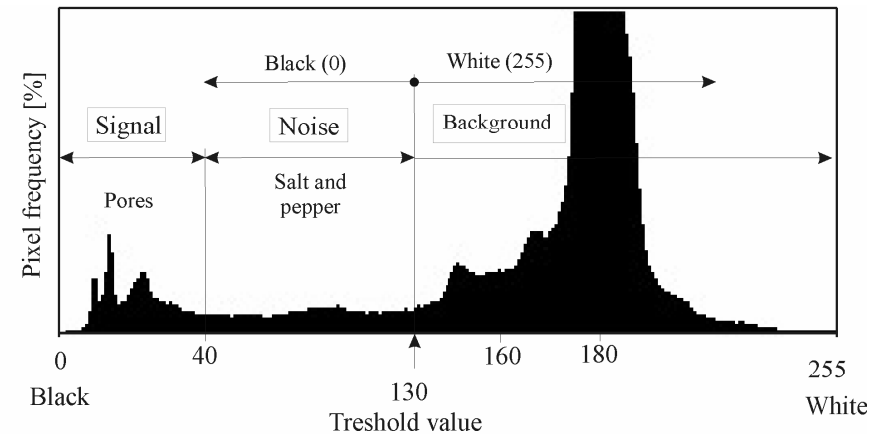

(b) Histogram of gray shades

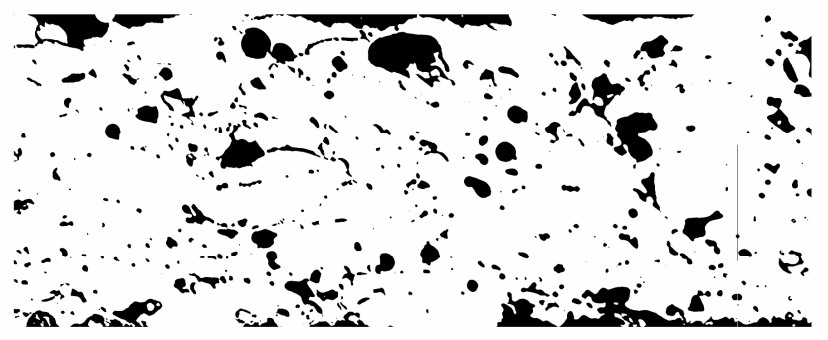

(d) Image after binarisation

Fig. 3. Metallographic image of the Ni-Cr-B-Si coating, (a) Initial image of coating and base material in grayscale - measuring field (1000 $4400 \mu \mathrm{m})$, (b) histogram of grey values [0-255] (c) cropped initial image in grayscale, (d) image after binarisation

Fig. 4a shows the images after the segmentation with different threshold values. When the threshold value is 40 , the image of the pores is clean but their size and number are underestimated. The threshold values of 160 and 180 , on the other hand, are not adequate in this case as the image displays the coating background. For the image shown in Fig. 3a, the threshold value of 130 was manually selected from the histogram in Fig. 3b. The threshold values for other images can vary depending on the contrast and brightness of the image thus slightly influences the apparent porosity content.

The median filter with possibility to set the circular kernel radius applied to reduce the rest of the salt and pepper noise. The radius must be set to a point where the noise is reduced, but the porosity area and edge is maintained as much as possible to obtain reliable results.

The smallest radius of 1 does not remove the noise so efficiently and consequently, therefore the number of small pores would be overestimated. The radius of 2 slightly influence the pore edges and can also underestimate the porosity content, but salt and pepper noise was removed efficiently. On Fig. 4b, the noise was satisfactorily removed with median filter $\mathrm{r}=2$, therefore it is no need to use higher radius size. 


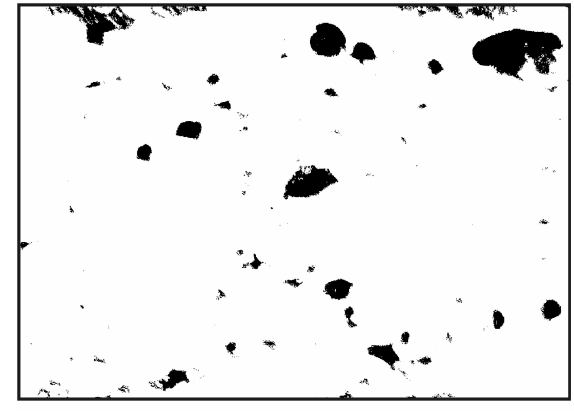

1. Threshold 40

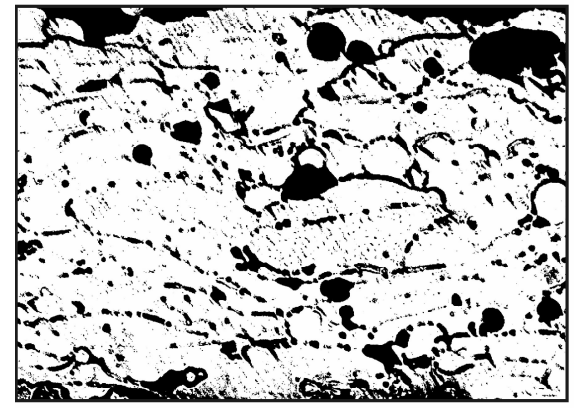

3. Threshold 160

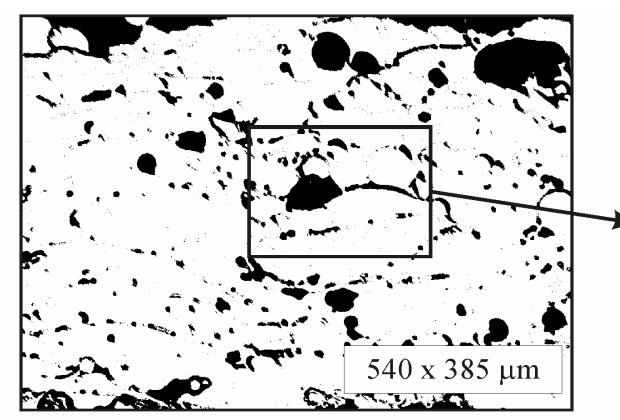

2. Threshold 130

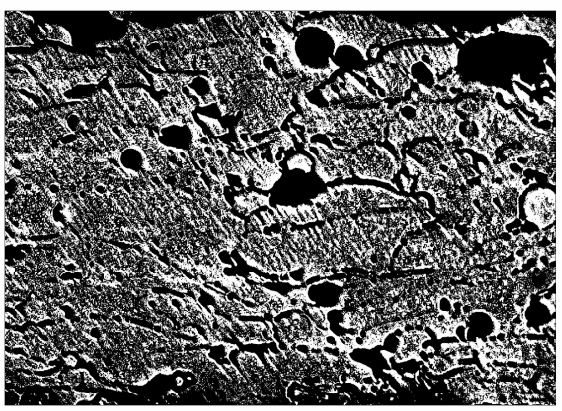

4. Threshold 180

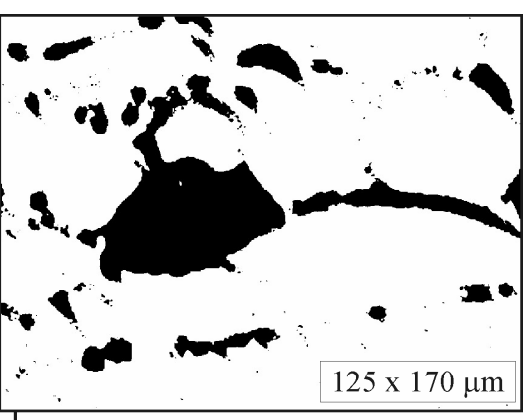

Before median filter (7663 objects)

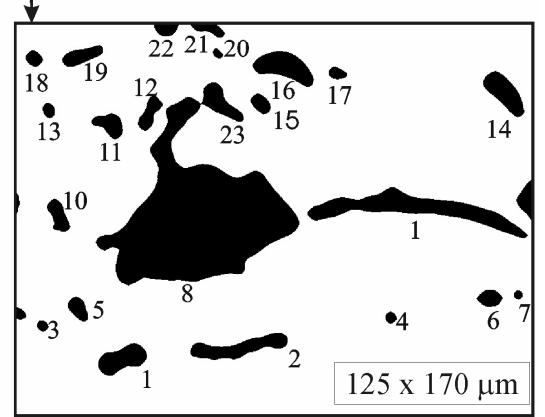

After median filter (23 objects)

(b) The effect of median filter with $\mathrm{r}=2$

(a) Metalographic image after segmentation with different treshold values

Fig. 4. Image pre-processing steps; (a) image segmentation using different threshold values: 40, 130, 160, and 180; (b) effect of the median filter with a radius of 2.

\section{RESULTS}

\section{AREA PERCENTAGE POROSITY AFTER FLAME SPRAYING}

Area percentage porosity equals the area percentage of black pixels on the binary image. The number of the measuring fields which should be analyzed in order to obtain the average value of a sample within the confidence interval selected depends on the homogeneity, density and size of the analyzed objects. An estimate of a sufficient number of fields was obtained by analyzing the nine coated specimens. Five measuring fields in each sample were determined to calculate the average $\overline{\mathrm{X}}$ and standard deviation $\overline{\mathrm{S}}$. The relative standard error was calculated as $\operatorname{RS}_{\mathrm{e}}=\overline{\mathrm{S}} /(\overline{\mathrm{X}} \cdot \sqrt{\mathrm{n}})$, where $\mathrm{n}$ is the number of fields. The results are given in Table 2. The number of necessary fields was calculated based on the sample taken from specimen No. 2, where the standard error $\mathrm{RS}_{\mathrm{e}}$ of area percentage porosity is the highest. The biggest number of specimens is needed in this case. The mean area percentage porosity for all tests is $10.2 \%$.

Table 2. Area percentage porosity after flame spraying applied to nine specimens.

\begin{tabular}{|c|c|c|c|c|c|c|c|c|c|c|}
\hline$\#$ & $\mathrm{n}_{\mathrm{i}}$ & $\mathrm{n}_{\mathrm{i} 1}$ & $\mathrm{n}_{\mathrm{i} 2}$ & $\mathrm{n}_{\mathrm{i} 3}$ & $\mathrm{n}_{\mathrm{i} 4}$ & $\mathrm{n}_{\mathrm{i} 5}$ & $\overline{\bar{X}}$ & $\overline{\mathrm{S}}$ & $\mathrm{S}_{\mathrm{e}}$ & $\mathrm{RS}_{\mathrm{e}}$ \\
\hline 1 & 5 & 9.9 & 10.8 & 10.9 & 10.5 & 10.2 & 10.5 & 0.416 & 0.186 & 0.018 \\
\hline 2 & 10 & 6.7 & 10.0 & 11.6 & 11.2 & 8.5 & 9.6 & 2.021 & 0.904 & 0.094 \\
\hline 3 & 15 & 14.5 & 11.2 & 8.9 & 13.2 & 10.5 & 11.7 & 2.214 & 0.990 & 0.085 \\
\hline 4 & 20 & 9.2 & 10.6 & 10.5 & 10.2 & 11.5 & 10.4 & 0.828 & 0.370 & 0.036 \\
\hline 5 & 25 & 13.3 & 10.4 & 10.5 & 13.1 & 12.5 & 12.0 & 1.410 & 0.631 & 0.053 \\
\hline 6 & 30 & 11.3 & 11.7 & 7.8 & 9.8 & 11.5 & 10.4 & 1.645 & 0.736 & 0.071 \\
\hline 7 & 35 & 8.9 & 10.3 & 8.7 & 9.5 & 10.6 & 9.6 & 0.837 & 0.374 & 0.039 \\
\hline 8 & 40 & 5.9 & 8.4 & 7.8 & 8.9 & 9.5 & 8.1 & 1.380 & 0.617 & 0.076 \\
\hline 9 & 45 & 10.8 & 9.4 & 7.7 & 10.1 & 9.8 & 9.6 & 1.159 & 0.518 & 0.054 \\
\hline Sum & & & & & & & 10.2 & 1.323 & & \\
\hline
\end{tabular}


The number of the measuring fields required to estimate the sample average in a $95 \%$ confidence interval, so that the estimation will not deviate for more than $\pm 10 \%$ from the real value (Kališnik, 2002), is:

$$
\mathrm{n}=\left(\frac{200}{\mathrm{y}} \cdot \frac{\overline{\mathrm{S}}^{2}}{\overline{\mathrm{X}}}\right)=9
$$

where $\mathrm{y}$ is deviation $(\mathrm{y}=10 \%)$. The $\mathrm{n}=9$ number of fields was chosen for further sample analysis after the heat treatment.

\section{AREA PERCENTAGE POROSITY AFTER HEAT TREATMENT}

Table 3 lists area porosity percentage after the heat treatment, with the average porosity $\bar{P}_{i}$ of the nine fields and the standard deviation $\mathrm{S}$. The lowest average porosity of $0.83 \%$ was measured after the heat treatment with partial remelting, with 5 minutes of holding time, at a temperature of $1080^{\circ} \mathrm{C}$.

Table 3. Area percentage under different temperaturetime conditions.

\begin{tabular}{ccccc}
\hline$\#$ & $\mathrm{~T}\left[{ }^{\circ} \mathrm{C}\right]$ & $\mathrm{t}[\mathrm{min}]$ & $\overline{\mathrm{P}}_{\mathrm{i}}[\%]^{\mathrm{c}}$ & $\mathrm{S}[\%]^{\mathrm{b}}$ \\
\hline 1 & 930 & 5 & 2.27 & 0.6 \\
2 & 930 & 10 & 2.10 & 0.9 \\
3 & 930 & 20 & 2.70 & 0.9 \\
4 & 1040 & 5 & 1.27 & 0.2 \\
5 & 1040 & 10 & 0.77 & 0.2 \\
6 & 1040 & 20 & 0,87 & 0,5 \\
7 & 1080 & 5 & 0,83 & 0,1 \\
8 & 1080 & 10 & 0,87 & 0,1 \\
9 & 1080 & 20 & 1,30 & 0,2 \\
\hline
\end{tabular}

\section{ANALYSIS OF VARIANCE}

A variance analysis is used to estimate the significance of each investigated parameter, using the nullhypothesis test (Montgomery, 2008) which calculates the sum of squares, interaction, and experi-mental error. The mean square is the ratio between the sum of squares of each parameter and the number of degrees of freedom. The experimental F-values and statistical $F_{0}$ values are compared for temperature $T$, time $t$, and interaction (Txt). The F-value is the ratio between the mean square $\mathrm{MS}_{\text {factor }}$ and the mean square of error $\mathrm{MS}_{\mathrm{er}}$. The statistical significance criteria of a parameter are:

$$
\mathrm{F}_{\alpha ; \mathrm{DF}_{\mathrm{f}} ; \mathrm{DF}_{\mathrm{er}}}>\mathrm{F}_{0}=\frac{\mathrm{MS}_{\text {factor }}}{\mathrm{MS}_{\mathrm{er}}}
$$

where $\mathrm{F}_{\alpha ; \mathrm{DF}_{\mathrm{f}} ; \mathrm{DF}}$ is the value of test F-statistic at a confidence value of $\alpha=0,05 ; \mathrm{DF}_{\mathrm{f}}$ is the number of degrees of freedom; and $\mathrm{DF}_{\mathrm{er}}$ is the error number of degrees of freedom. The results of the area percentage porosity variance analysis are given in Table 4.

It can be concluded, based on the results given in Table 4, that the parameter temperature (T) at a confidence level of $\alpha=0.05$ is significant; therefore, the null hypothesis is confirmed $\left(\mathrm{F}_{0,05 ; 2 ; 18}=3.55<\right.$ 23.819). The heat-treatment time $(\mathrm{t})$ is not significant; therefore, the null hypothesis is rejected. Consequently, statistical data reveal that parameter interactions are weak $\left(\mathrm{F}_{0,05 ; 4 ; 18}=3.00>0.52\right)$.

Figs. 5a and $5 \mathrm{~b}$ show the interaction charts as functions of heat-treatment temperature and time. The porosity values are the highest in the samples heattreated at a temperature of $930^{\circ} \mathrm{C}$. At $1040^{\circ} \mathrm{C}$ and $1080^{\circ} \mathrm{C}$, the differences in porosity are rather insignificant. At a temperature of $1080^{\circ} \mathrm{C}$, area porosity percentage is the lowest in the 5-min remelting, while it slightly increases in the 10 - and 20 -min remelting.

Table 4. Variance analysis used to estimate the influence of temperature and time on porosity $(n=9)$.

\begin{tabular}{lccccc}
\hline Source of variation & Sum of Squares & Degrees of freedom & Mean Square & F-value & P-value \\
\hline Temperature T & 1152 & 2 & 575.77 & 23.819 & $1 \mathrm{E}-4$ \\
Time t & 83 & 2 & 41.508 & 1.717 & 0.209 \\
Interaction T x t & 51 & 4 & 12.699 & 0.525 & 0.722 \\
Error & 435 & 18 & 24.172 & & \\
\hline Total & 1720 & 26 & & & \\
\hline
\end{tabular}




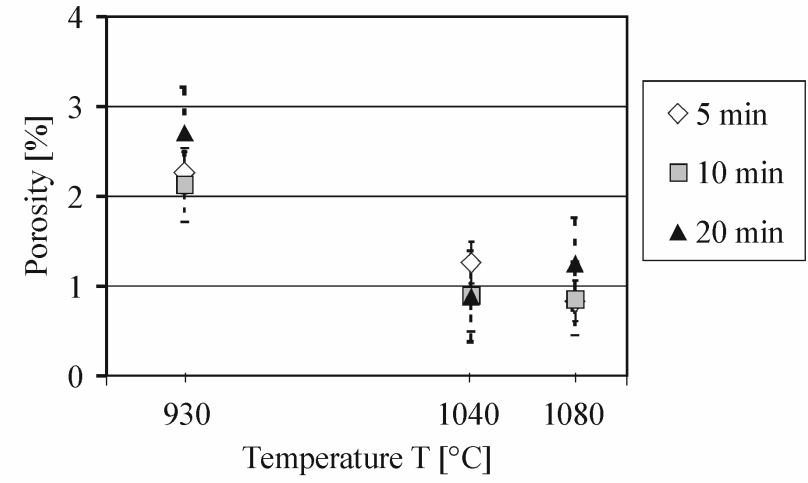

(a) Porosity as a function of temperature $\mathrm{T}$

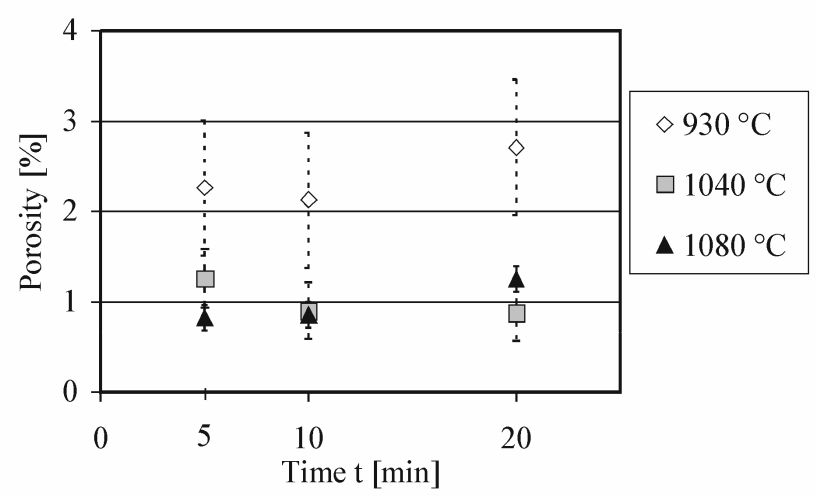

(b) Porosity as a function of time $\mathrm{t}$

Fig. 5. Interaction charts of average area percentage porosity.

\section{PORE SHAPE BEFORE AND AFTER HEAT TREATMENT}

Two typical binary images of porosity after flame spraying and after heat treatment $\left(1080^{\circ} \mathrm{C}, 5\right.$ minutes) are given in Figs. 6a and 6b, respectively. Fig. 6a shows a network of interconnected porosity which is a result of the shrinkage of the molten particles upon solidification in the flame-spraying process. After remelting coating in a furnace, the pores become less elongated and the shape more circular (spherical voids). Moreover, the area percentage porosity reduces from values above $10 \%$ to values below $1 \%$. The analysis is focused on the comparison of the pore equivalent diameter, major axis orientation, and elongation.

Histograms with fitted probability density functions (PDF) were used for the visualization of the selected variables. A histogram is a graph consisting of a number of vertical bars, into which the sample values are sorted. The height of each histogram bar indicates the number of data points that fall into each class, relative to the total number of data values.

The first step is to choose the number of bins, or classes, into which data will be sorted. There are several ways to do this, and one of the most commonly used methods is to define the number of bins based on the total number of observations:

$$
\mathrm{k}=1+\log _{2} \mathrm{~N},
$$

where $\mathrm{N}$ is the total number of data values, and $\mathrm{k}$ is the resulting number of bins. Non-integer number $\mathrm{k}$ should be rounded to the nearest integer. The number of objects should be larger than $30(\mathrm{~N}>30)$. The PDF has a constant shape, while the appearance of a histogram can change depending on the number of bins. Using a larger number of classes can make a histogram more detailed, but that will also introduce significant errors to the histogram. In this analysis, the number of bars was fixed to 15 .

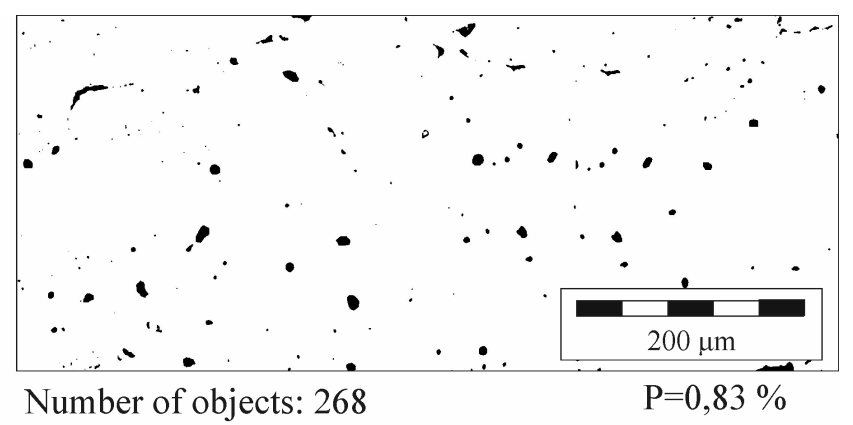

(b)

(a)

Fig. 6. The two typical binary images of porosity after flame spraying and after heat treatment; (a) a network of interconnected pores after flame spraying, (b) globular separated pores after heat treatment with partial remelting at $1080{ }^{\circ} \mathrm{C}$ with a 5-minute time interval. 


\section{EQUIVALENT DIAMETER}

A pore is an irregular 3-dimensional object in a coating's structure sectioned at a random location. The area of a sectioned pore in a 2-D plane depends on the section's location. To evaluate the area accurately, the number of test pores in a selected test field should be large. Equivalent diameter is a diameter of a circle with the same area as the pore and is calculated as:

$$
\mathrm{D}_{\mathrm{f}}=\sqrt{4 \mathrm{~A} / \pi},
$$

where $D_{f}$ is the equivalent diameter and $A$ is the pore area. The EasyFit Professional statistical software (v5.4) used to fit different PDF's and compare the adequacy of the fit with the Kolmogorov-Smirnov test was used to analyze the porosity. The KolmogorovSmirnov statistics quantifies the distance between the empirical distribution function of the sample and the cumulative distribution function of the reference distribution, or between the empirical distribution functions of two samples (Grabec et al., 2000). The histogram of the equivalent diameter is nonsymmetrical with a peak on the left side of the histogram. The fitted PDF should be skewed to the left. Among the non-negative 2-parametric functions available in the program, the inverse Gaussian 2-parametric function fits data the best. Inverse Gaussian function is defined as:

$$
f(x)=\sqrt{\frac{\lambda}{2 \pi(x)^{3}}} \cdot \exp \left(-\frac{\lambda(x-\mu)^{2}}{2 \mu^{2}(x)}\right),
$$

where $\lambda$ and $\mu$ are continuous parameters that defines the shape of curve. To compare the experimental histogram with fitted $\operatorname{PDF}(\mathrm{x})$, the vertical scale must be scaled to compare function with the histogram. In this case, the area under scaled $\operatorname{PDF}(\mathrm{x})$ will not be equal to 1 anymore.

Fig. 7a shows the histogram and PDF for the equivalent diameter after spraying and Fig. $7 \mathrm{~b}$ after heat treatment at $1080^{\circ}$ in 5 minutes. Both curves are similar in shape but shifted to the left because the equivalent diameters are much smaller after the heat treatment. The average equivalent diameter after heat treatment reduces from $13.8 \mu \mathrm{m}$ to $3.6 \mu \mathrm{m}$.



(a)

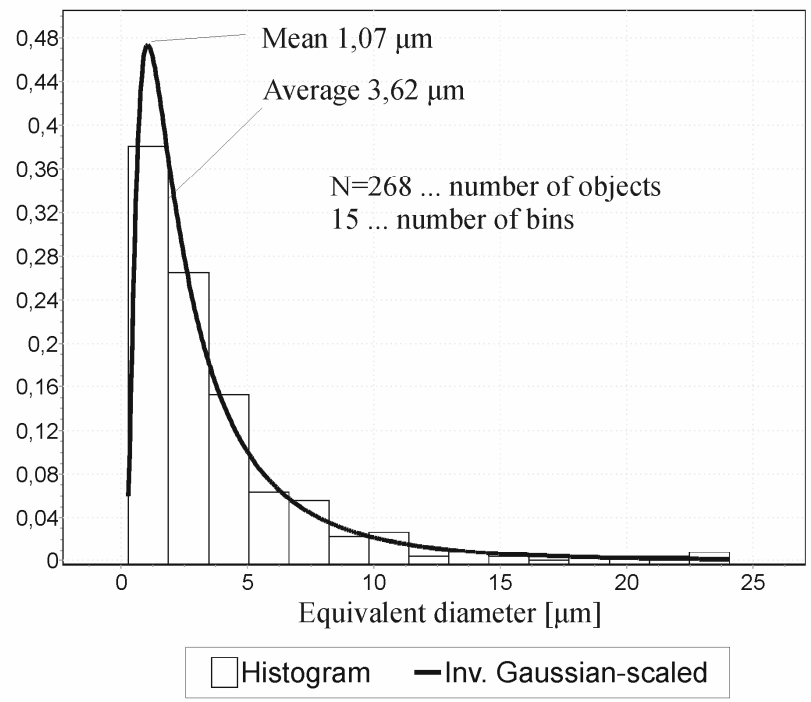

(b)

Fig. 7. The equivalent diameter (a) after spraying, (b) after heat treatment with partial remelting at $1080{ }^{\circ} \mathrm{C}$ in 5-minute time interval (note: the vertical axis of $\operatorname{PDF}(x)$ is scaled in order to overlay and compare it with the histogram).

\section{MAJOR AXIS ANGLE}

The major axis of an object is its longest distance between two edge points, a line that runs through the center. The major axis angle analysis reveals that this parameter is a good indicator of lamellar porosity presence in coatings. The minor axis also runs through the center, normal to the major axis (Fig. 8). 


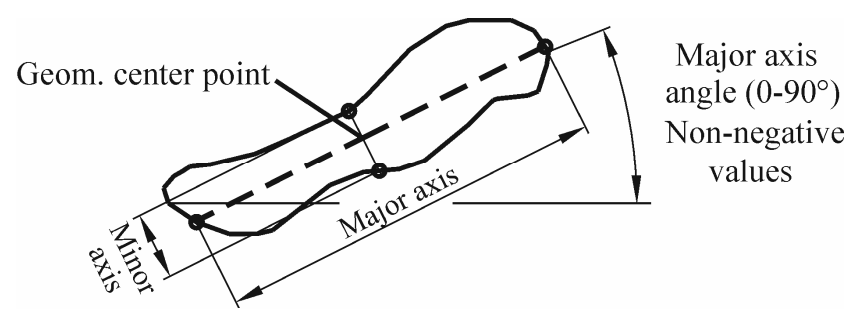

Fig. 8. Major and minor axis and major axis angle definition.

Angles are represented as absolute values between $0^{\circ}$ and $90^{\circ}$. The angle of the major axis pores near $0^{\circ}$ indicates lamellar porosity. After spraying, the deformation and shrinkage of the particles lead to the formation of narrow, long pores which are horizontally oriented. Fig. 9 indicates the bimodal distribution of major axis angles with the first peak at about $10^{\circ}$ and the second peak appears at $70^{\circ}$.



$\square$ Histogram

Fig. 9. Major axis angle after flame spraying.

\section{PORE ELONGATION}

The elongation of the pores is an important parameter related to coating performance and endurance, and a network of interconnected elongated pores is not a favorable result. Literature shows various equations to calculate elongation. The simplest elongation definition is the ratio between the major and minor axis length:

$$
\mathrm{E}=\mathrm{D}_{\min } / \mathrm{D}_{\text {max }},
$$

where $E$ is elongation, $D_{\min }$ the minor axis, and $D_{\max }$ the major axis. If the average or median elongation distribution is about 1 , the pores are more circular; if it is about 0 , the pores are long and narrow. Fig. 10 represents the elongation distribution of after the spraying and heat treatment at $1080^{\circ} \mathrm{C}$ with a 5minute time interval. After flame spraying, the PDF can be described with the error function. The error function is symmetrical and unbounded; the parameters $\mathrm{k}$ and $\sigma$ define the peak of the middle part of the distribution.

After heat treatment, the histogram is best fitted with right skewed unbounded Gumbel PDF. The Gumbel PDF with a peak close to 1 indicates and confirms the globular pore shape after heat treatment. After heat treatment, the number of narrow, long pores greatly reduces with mode at 0.77 .

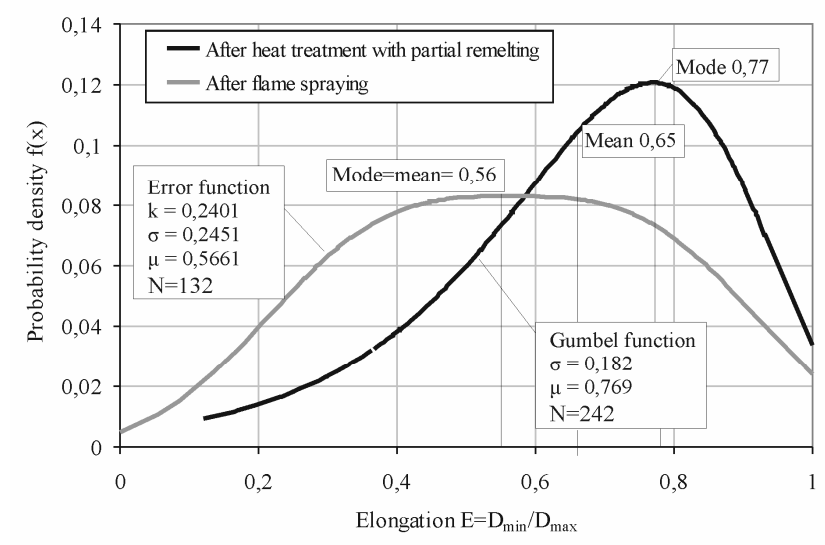

Fig. 10. Probability density functions for pore elongation, symmetrical and blunt peak of error PDF function after flame spraying and right-skewed Gumbel $P D F$ function after heat treatment at $1080{ }^{\circ} \mathrm{C}$ with a 5-minute time interval.

\section{CONCLUSION}

The image pre-processing technique presented in this study is one of the possibilities to evaluate the porosity area percentage, distribution of equivalent pore diameter and their major axis orientation. Special care must be paid not to damage the coating during the metallographic preparation to avoid artefacts and measurement biases. A number of experiments were conducted to select the optimal temperature-time conditions for minimizing area percentage porosity and to compare pore shape parameters on metallographic specimens after flame spraying and subsequent furnace remelting. Based on these examinations, the following conclusions can be drawn:

- Area percentage porosity and pore shape can be influenced by a controlled furnace heat-treatment method with a partial Ni-Cr-B-Si coating remelting process. The minimal porosity value was determined in the coating remelted at a temperature of $1080^{\circ} \mathrm{C}$ with a 5 -min time interval. Area percentage porosity reduced drastically from the initial $10.2 \%$ 
to $0.8 \%$ after the heat treatment. The variance analysis of the heat-treated samples points to temperature (T) as the influential parameter, while time (t) had no significant effect on area percentage porosity.

- After heat treatment with partial remelting at $1080^{\circ} \mathrm{C}$, the average equivalent diameter reduces from the initial $13.8 \mu \mathrm{m}$ in as-sprayed condition to the final value of $3.62 \mu \mathrm{m}$ after the remelting. The equivalent diameter histogram fits well to the inverse Gaussian distribution function.

- The analysis of the major axis angle orientation after spraying reveals a higher frequency of smaller major axis angles which confirms the horizontallamellar nature of thermal-sprayed coatings. The particle deformation and their rapid solidification and shrinkage lead to a higher number of unfavorable thin and interconnected pores. After the heat treatment with remelting, there is no preferential pore orientation.

- The pore elongation analysis shows that, on average, a coating's pore shape after the heat treatment with partial remelting is less elongated and more circular/spherical. Also, the network of interconnected pores in coatings after the flame spraying is eliminated. Small diameter pores exist as separated spherical voids. Porosity cannot be completely eliminated; however, the remelting process considerably reduces the initial porosity, that is, increases the coating density.

\section{REFERENCES}

Bergant Z, Grum J (2009). Quality improvement of flame sprayed, heat treated, and remelted NiCrBSi coatings. $\mathrm{J}$ of thermal spray tech 18:380-91.

Davis JR (2004). Handbook of Thermal Spray Technology. ASM International, Materials Park, $\mathrm{OH}$.

Desphande S, Kulkarni A, Sampath S, Herman H (2004). Application of image analysis for characterization of porosity in thermal spray coatings and correlation with small angle neutron scattering. Surf Coat Tech 187:6-16.

Desphande S, Sampath S, Zhang H (2005). Mechanisms of oxidation and its role in microstructural evolution of metallic thermal spray coatings - Case study for NiAl. Surface Coat Tech 200:5395-406.
Gonzales R, Garcia MA, Penuelas I, Cadenas M, Fernandez MR, Battez AH, et al. (2007). Microstructural study of NiCrBSi coatings obtained by different processes. Wear 263:619-24.

Grabec I, Gradišek J (2000). Description of random phenomena (In Slovene). Faculty of Mechanical Engineering, Ljubljana, 149-51.

Kališnik M (2002). Stereology fundamentals (In Slovene). Society for stereology and quantitative image analysis (In Slovene), 99-109.

Kenneth R, Castleman, Qiang W (2008). Microscope image analysis. Object Classification, Elsevier, Ch. 11, 221-46.

Kim HJ, Hwang SJ, Lee CH, Juvanon P (2003). Assessment of wear performance of flame sprayed and fused Nibased coatings. Surf Coat Tech 172:262-9.

Kumar AD (2000). Stereometric analysis and relation between the porosity of sprayed and sintered $\mathrm{NiCrBSi}$ plasma spray protective coating. J Mat Proc Tech 101: 322-31.

Montgomery DC, (2008). Design and Analysis of experiments, $7^{\text {th }}$ edition. New York: John Willey \& Sons.

Neithalath N, Sumanasooriya MS, Deo O (2010). Characterising pore volume, sizes and connectivity in pervious concretes for permeability prediction. Materials characterisation 61:802-13.

Nutal N, Gommes CJ, Blancher S, Pouteau P, Pirard J, Boschini F (2010). Image analysis of pearlite spheroidization based on the morphological charact-erization of cementite particles. Image Anal Stereol 29:91-8.

Serres N, Hlawka F, Costil S, Langlade C, Machi F (2010). Microstructures and environmental assessment of metallic NiCrBSi coatings manufactured via hybrid plasma spray process. Surface and coatings Technology, doi:10.1016/jsurfcoat.2010.03.048.

Shrestha S, Neville A, Hodgkiess T (2001). The effect of Post-Treatment of a High-Velocity Oxy-Fuel Ni-CrMo-Si-B coating Part I: Microstructure/Corrosion Behaviour Relationships J Therm Spr Tech 10:470-9.

Standard Guide for Metallographic Preparation of Thermal Sprayed Coatings, (2003). E 1920-03, Annual Book of ASTM Standards, ASTM International, West Conshohocken, PA, 03.01., 2003.

Test Methods For Determining Area Percentage Porosity in Thermal Sprayed Coatings (2003). ASTM Standard E2109-01, ASM International, West Conshohocken, PA, 03.01. 